\title{
Hydrothermal activity revealed by rock magnetic anomaly from core sediments in the southern Okinawa Trough
}

\author{
Yin-Sheng Huang ${ }^{1, *}$, Chih-Chieh Su ${ }^{2}$, Wen-Bin Doo ${ }^{1}$, Shu-Kun Hsu ${ }^{1,3}$, Chin-Hui Tsai ${ }^{1}$, \\ Hsueh-Fen Wang ${ }^{1}$, Shiao-Shan Lin ${ }^{1}$, Chin-Wei Liang ${ }^{1}$, Jing-Yi Lin ${ }^{1,3}$, Jui-E Chen ${ }^{4}$, \\ Yi-Jung Lin ${ }^{4}$, and Yunshuen Wang ${ }^{4}$ \\ ${ }^{1}$ Center for Environmental Studies, National Central University, Taoyuan City, Taiwan \\ ${ }^{2}$ Institute of Oceanography, National Taiwan University, Taipei City, Taiwan \\ ${ }^{3}$ Department of Earth Sciences, National Central University, Taoyuan City, Taiwan \\ ${ }^{4}$ Central Geological Survey, Ministry of Economic Affairs, Taipei City, Taiwan
}

\author{
Article history: \\ Received 30 October 2018 \\ Revised 11 July 2019 \\ Accepted 31 July 2019 \\ Keywords: \\ Rock magnetic anomaly, Magnetic \\ susceptibility, Authigenic iron \\ sulfides, Hydrothermal activity, \\ Southern Okinawa Trough \\ Citation: \\ Huang, Y.-S., C.-C. Su, W.-B. \\ Doo, S.-K. Hsu, C.-H. Tsai, H.-F. \\ Wang, S.-S. Lin, C.-W. Liang, J.-Y. \\ Lin, J.-E. Chen, Y.-J. Lin, and Y. \\ Wang, 2019: Hydrothermal activity \\ revealed by rock magnetic anomaly \\ from core sediments in the southern \\ Okinawa Trough. Terr. Atmos. Ocean. \\ Sci., 30, 685-694, doi: 10.3319/ \\ TAO.2019.07.31.01
}

\begin{abstract}
The southern Okinawa Trough has been widely considered an important area with hydrothermal activity. Several active hydrothermal fields have been reported, especially around the Yonaguni Knoll IV. In this study, we collected marine sediment cores around the Yonaguni Knoll IV by using the R/V Ocean Research 1. Core sites with and without gas disturbance were selected based on the single-beam bathymetry (Chirp) by using the onboard echo sounder system. For the sites away from gas disturbance, which are generally considered showing the background situation in the southern Okinawa Trough, variations of the magnetic susceptibility in these cores are relatively stable with values about between $20 \times 10^{-5}$ and $60 \times 10^{-5} \mathrm{SI}$. As for the sites with clear gas-features detected by the Chirp sonar, the signature with dramatically changing magnetic susceptibility is observed in the cores. In general, gasfeatures are considered linking to the hydrothermal activity in the southern Okinawa Trough. Magnetic signature with such abruptly changing magnetic susceptibility could also be considered being caused by authigenic iron sulfides associated with the hydrothermal alternation. Therefore, the rock magnetic anomaly could be suggested as an indicator revealing the hydrothermal activity in the southern Okinawa Trough.
\end{abstract}

\section{INTRODUCTION}

Located behind the Ryukyu arc-trench system, the Okinawa Trough (OT), an active back-up spreading basin characterized by many rifting features, extends over $1200 \mathrm{~km}$ from Japan to Taiwan along the eastern Eurasian continental margin (Sibuet et al. 1987, 1998). It can usually be divided into three segments, the northern OT, middle OT, and southern OT. In general, the OT is considered an area of extensive volcanism with hydrothermal activity. Several hydrothermal venting fields have been discovered along the OT (Ishibashi et al. 2015; Watanabe and Kojima 2015). In

\footnotetext{
* Corresponding author

E-mail:yinson@ncu.edu.tw
}

the southern OT, the Yonaguni Knoll IV is an important area with hydrothermal activity (Suzuki et al. 2008). Four active hydrothermal fields with high temperature venting fluids were discovered around the Yonaguni Knoll IV (Fujikura 2001). Smokey black fluids with the highest temperature could reach over $320^{\circ} \mathrm{C}$ at these active hydrothermal fields (Suzuki et al. 2008).

Hydrothermal system on the Galápagos Rift was first reported by Corliss et al. (1979). Nowadays, more than 300 hydrothermal fields around the world have been discovered (Hannington et al. 2011). In general, products of hydrothermal activity contain mixing of hot metal-rich hydrothermal fluids and mixtures of sulfides and hydrogen sulfide. When 
these hot fluids extrude out of seafloor and mix with cold seawaters, dissolved metals and sulfides would condense and deposit, and then form white or black smoker vents. Contents of these seafloor sulfides usually include authigenic iron sulfides such as pyrrhotite and pyrite because strong hydrothermal alteration would replace detrital magnetite by monoclinic pyrrhotite and pyrite (Urbat et al. 2000). In contrast to detrital magnetite, authigenic iron sulfides would significantly change the values of magnetic susceptibility (MS). In addition, during the process of the hydrothermal alteration, seafloor sulfides usually accompany with some metal-rich materials, such as $\mathrm{Cu}, \mathrm{Pb}, \mathrm{Zn}, \mathrm{Au}$, and $\mathrm{Ag}$ (Rona 2003; Cathles 2011; Hannington et al. 2011; Gena et al. 2013), even some rare earth elements (Hongo et al. 2007). Hydrothermal sites attract much attention due to these economic metals.

In this study, seven marine sediment cores were collected by using the R/V Ocean Research 1 (OR1). Core sites were selected considering gas or fluid emissions detected by using the onboard single-beam bathymetry (Chirp). MSCL (multi-sensors core logger) measurement was completed and MS and $\gamma$-density ( $\gamma$-ray density) records were first presented and discussed. Further, magnetic hysteresis measurements and X-ray diffraction (XRD) analyses were both applied to classify and identify the dominant magnetic minerals in the OR1 cores. By combining Chirp images, MSCL records, and magnetic analyses, we discuss rock magnetic properties of these cores and attempt to link gas-features with the rock magnetic signature caused by authigenic iron sulfides associated with the active hydrothermal system in the southern OT.

\section{MATERIALS AND METHODS}

To detect gas emissions such as gas-bubbles, gasflares, or gas-plumes, Chirp profiles, which are often used to identify and characterize the image in the seawater column, were collected by using the onboard echo sounder system (EK-60) during the OR1-1136 cruise in 2016 (Hsu 2016; Tsai et al. 2019). We therefore could select the core sites with or without gas disturbance by the Chirp images. In the study, the marine sediment cores were collected in the southern OT during the surveys of two OR1 cruises, OR11139 in 2016 (Su 2016) and OR1-1164 in 2017 (Su 2017).

In total, seven cores were obtained at six sites (Fig. 1). Detailed information of the cores is listed in Table 1. The cores A2, A3, and A4 were collected at the locations away from gas disturbance and the cores A6, G1, and P1 were obtained at the sites where gas or fluid activity was detected by onboard Chirp sonar (Figs. 1 and 2). The core G1 was collected at the site named Geolin Mounds (GLM) and the core P1 was obtained at the site named Penglai Fault Zone (PFZ). In fact, a core site was also planned on the Yonaguni Knoll IV but only some brittle rocks with black volcanic glasses were retrieved. Another important feature is that there were strong smells of hydrogen sulfide when some cores were retrieved onboard during the OR1 coring. This feature gives an important sign indicating whether the cores were affected by gases or not.

MSCL measurement was first done and core surface photographs were then taken after splitting the cores into working and archive halves in the Core Laboratory, Taiwan Ocean Research Institute (TORI). In this study, MS and $\gamma$-density records from MSCL measurement are used to discuss the core sediment properties. Based on core descriptions, core sediments are mostly composed of homogeneous silty grains with colors of dark-green, dark-gray, or dark-brown. No clear sandy or turbidity layer is visible and only some thin layers with fine grain silty sands are found in some core sections. Note that some cores have been affected by gas or fluid disturbance, and we will describe and discuss the feature in detail latter.

Magnetic hysteresis parameters were applied to characterize magnetic properties for the OR1 cores. Core sediments were filled in small capsules (about $0.5 \mathrm{~g}$ for each sample), and the measurement was done at room temperature by using the vibrating sample magnetometers (VSM). Four parameters from hysteresis loops were obtained, including saturation magnetization (Ms), saturation remanence magnetization $(\mathrm{Mr})$, coercivity $(\mathrm{Hc})$, and remanence coercivity (Hcr). The Day plot (Day et al. 1977) graphed by the ratios of $\mathrm{Mr} / \mathrm{Ms}$ and $\mathrm{Hc} / \mathrm{Hcr}$ is usually used to present the hysteresis parameters. Different magnetic minerals, such as detrital magnetite and authigenic iron sulfides, have different hysteresis behaviors so the ratio distribution on the Day plot may also be different. By using the Day plot, Horng et al. (2016) have developed a convenient way to identify and classify magnetic minerals probably affected by the gas hydrates dissociation.

Further, the XRD analysis was applied to identify and confirm dominant magnetic minerals in these cores. Magnetic minerals were extracted from sediments by using a rare earth magnet housed in a plastic tube. The XRD scan was run from 4 to 80 degree of $2 \theta$ and the results were presented after removing the background trend. Detail descriptions about the methods and applications for identifying and classifying magnetic minerals can be referred to the references (Horng and Chen 2006; Horng et al. 2016; Horng 2018).

\section{RESULTS}

\subsection{Core Sites Away from Gas or Fluid Disturbance}

Core results from the sites without gas or fluid disturbance (A2, A3, and A4) are first presented (Figs. 3a-c). These sites are away from the areas where active gas-plumes were detected (Fig. 1), and could be considered representing the general (background) deposition situation of the southern OT. By the core surface photographs, we observe that most core sediments are composed of uniform and homogeneous 


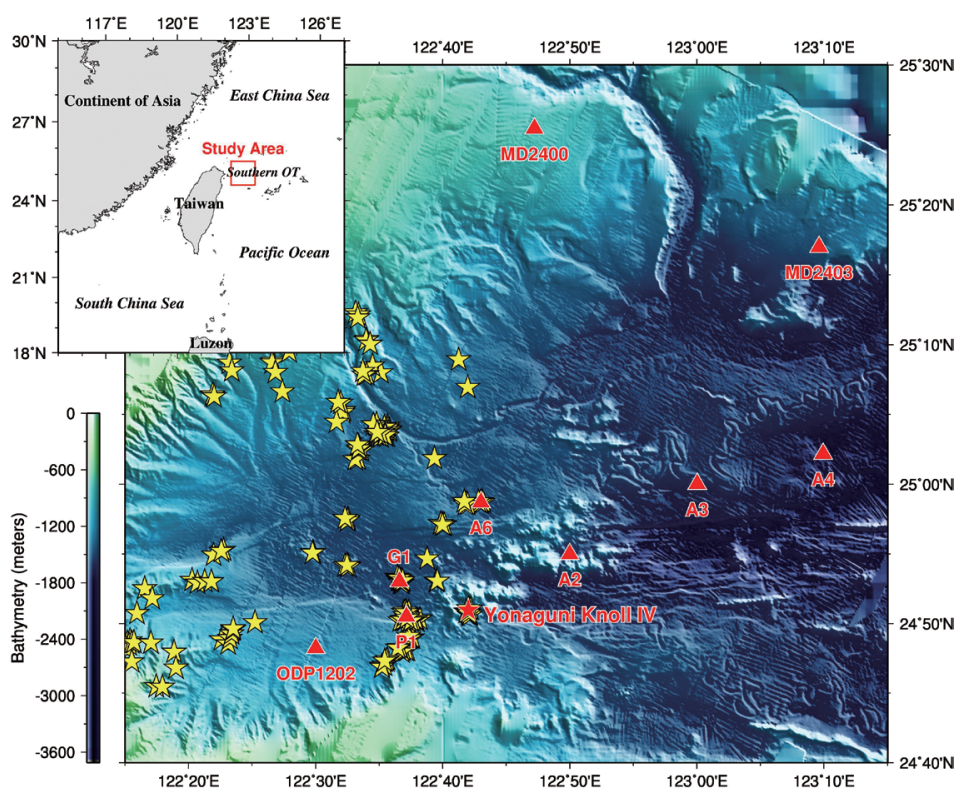

Fig. 1. Bathymetry map of the study area. Red triangles give the sites of the MD, ODP, and OR1 cores used in the study. Red star marks the location of the Yonaguni Knoll IV. Yellow stars show the locations where gas-plumes were detected by using the onboard Chirp sonar. Southern OT: Southern Okinawa Trough.

Table 1. Information of the OR1 cores used in the study.

\begin{tabular}{ccccc}
\hline Core names & Longitude (degree) & Latitude (degree) & Water depth $(\mathbf{m})$ & Core Length $(\mathbf{c m})$ \\
\hline OR1-1139-A2 & $122^{\circ} 49.9980^{\prime}$ & $24^{\circ} 54.9820^{\prime}$ & 1583 & 125 \\
OR1-1139-A3 & $123^{\circ} 00.0110^{\prime}$ & $25^{\circ} 00.0070^{\prime}$ & 1609 & 99 \\
OR1-1139-A4 & $123^{\circ} 09.9220^{\prime}$ & $25^{\circ} 02.1680^{\prime}$ & 1843 & 99 \\
OR1-1139-A6 & $122^{\circ} 42.9950^{\prime}$ & $24^{\circ} 58.7080^{\prime}$ & 1477 & 139 \\
OR1-1139-P1 & $122^{\circ} 37.1380^{\prime}$ & $24^{\circ} 50.4910^{\prime}$ & 1515 & 119 \\
OR1-1164-P1 & $122^{\circ} 37.2014^{\prime}$ & $24^{\circ} 50.6828^{\prime}$ & 1483 & 115 \\
OR1-1164-G1 & $122^{\circ} 36.5856^{\prime}$ & $24^{\circ} 53.0182^{\prime}$ & 1510 & 135 \\
\hline
\end{tabular}

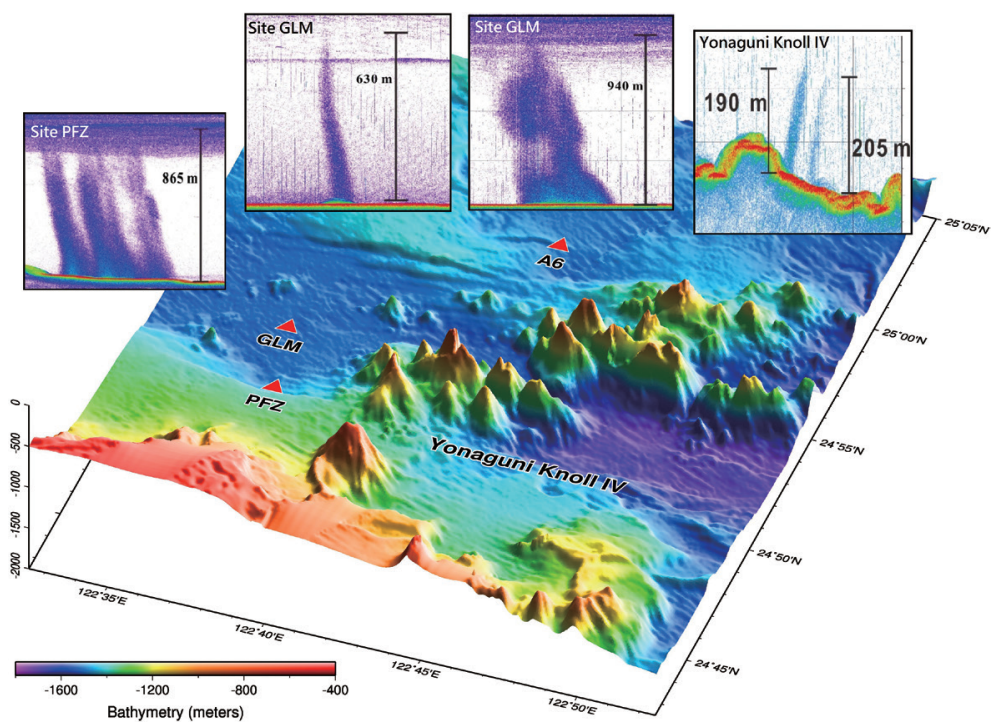

Fig. 2. Detailed topography around the Yonaguni Knoll IV. Red triangles mark the sites of the OR1 cores nearby the Yonaguni Knoll IV. The upper four panels give some examples of the Chirp images showing gas-plumes of these sites (Hsu 2016, 2017; Tsai et al. 2019). 
(a) Surface Image $\quad$ MS $\left(10^{-5} \mathrm{SI}\right) \quad \gamma$-Density $(9 / \mathrm{cc})$

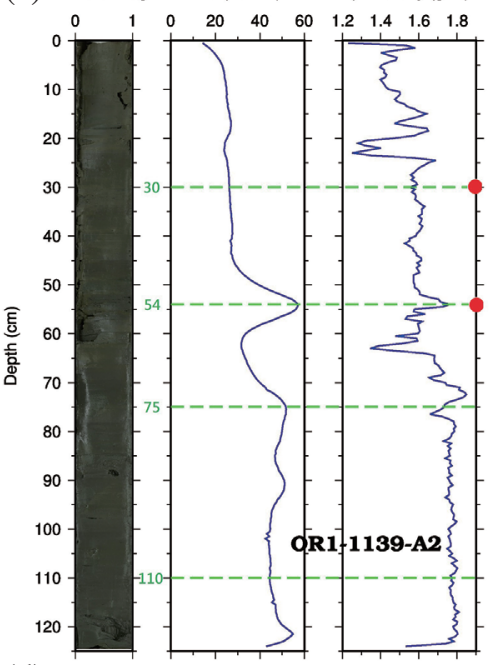

(b) Surface Image $\quad \operatorname{MS}\left(10^{-5} \mathrm{SI}\right) \quad \gamma$-Density $(g / c)$

(c) Surface Image $\quad \mathrm{MS}\left(10^{-5} \mathrm{SI}\right) \quad \gamma$-Density (g/cc)

(d) Surface Image $\mathrm{MS}\left(10^{-5} \mathrm{SI}\right)$

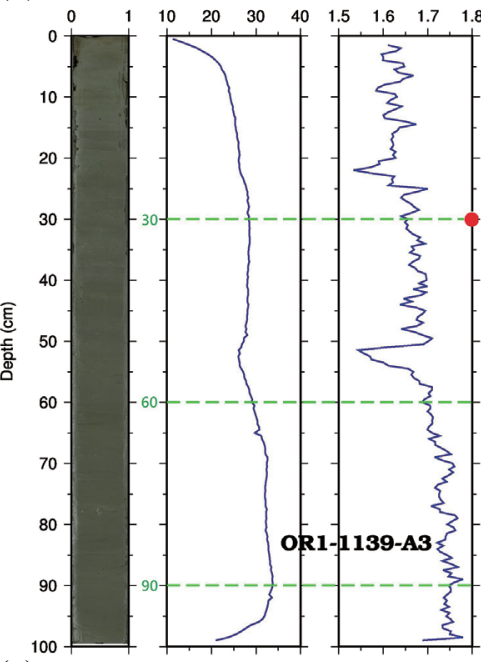

(e) Surface Image MS $\left(10^{-5} \mathrm{SI}\right) \quad \gamma$-Density $(g / \mathrm{cc})$
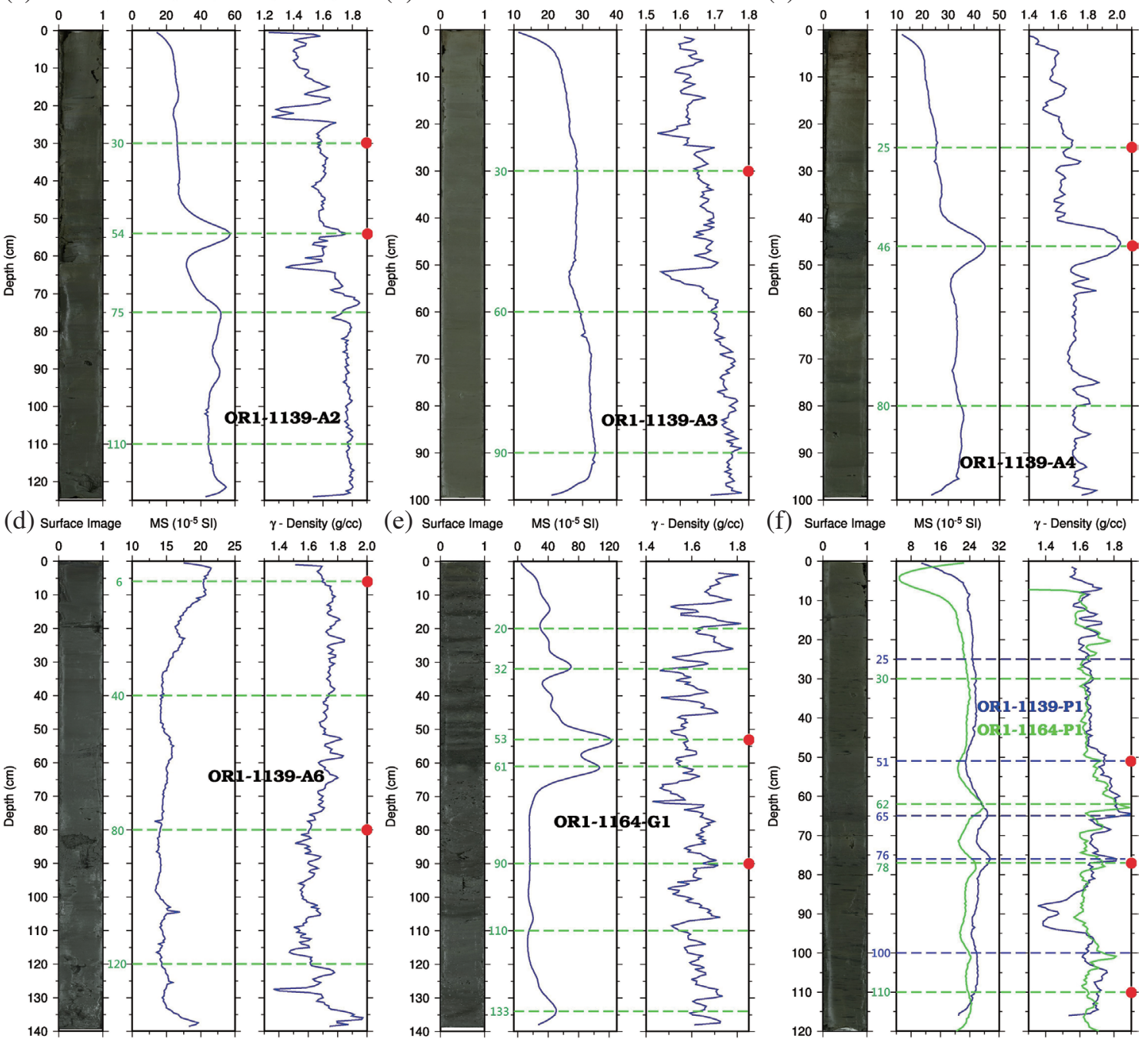

(f) Surace Image $\operatorname{MS}\left(10^{-5} \mathrm{SI}\right) \quad \gamma$-Density (g/cc)

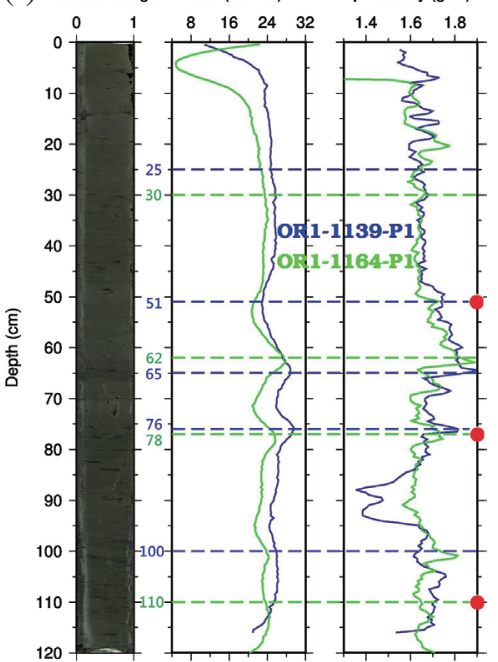

Fig. 3. Surface images, magnetic susceptibility (MS), and $\gamma$-ray density ( $\gamma$-density) of the cores analyzed in this study. (a) OR1-1139-A2; (b) OR11139-A3; (c) OR1-1139-A4; (d) OR1-1139-A6; (e) OR1-1164-G1; (f) OR1-1139-P1 and OR1-1164-P1. Green and blue dashed lines with numbers mark the sampling layers for the VSM measurement. Red dots give the sampling depths for the XRD analysis.

silts with color of dark-green or dark-brown (Figs. 3a - c). Overall, MS variations of these cores are relatively stable, especially the core A3. Most MS values fall between $20 \times$ $10^{-5}$ and $60 \times 10^{-5} \mathrm{SI}$ and $\gamma$-density values are about between 1.4 and $1.8 \mathrm{~g} \mathrm{cc}^{-1}$ (Figs. 3a - c).

Some thin layers with fine grain silty sands can still be found in these cores. In the core A2, two silty sand layers are found at about $53-55$ and $70-76 \mathrm{~cm}$ core depths, respectively (Fig. 3a), while higher values of both MS and $\gamma$-density also appear at the corresponding intervals. In the core A4, a silty sand layer with clear peaks in both parameters is found between 42 and $48 \mathrm{~cm}$ as well (Fig. 3c). Moreover, a long-term trend seems to be embedded in both MS and $\gamma$-density records: both parameters decrease gradually from the bottom to top of the cores (Figs. 3a - c). Sediment compaction during deposition may be regarded as a common factor causing this pattern.

\subsection{Core Sites Influenced by Gases or Fluids}

For the cores obtained from the sites affected by gases or fluids detected by the onboard Chirp sonar (the sites A6 and GLM), surface photographs of both cores A6 and G1 show that most sediments are also composed of uniform and homogeneous silts with color of dark-green (Figs. 3d and e). In the core A6, a soupy-like feature indicating a relatively higher water content of the core sediments appears at the core bottom (Fig. 3d); in the core G1, a clear interface is found at $\sim 65 \mathrm{~cm}$ core depth (Fig. 3e). Several darker laminae associated with higher MS values are observed above this interface while the laminae become fewer and the sediments look more porous (i.e., higher porosity) below the interface (Fig. 3e).

In contrast to those cores without gas disturbance, MSCL variations of both cores A6 and G1 appear to be unusual, especially the MS records. Long-term variations of 
both MS and $\gamma$-density records of the core A6 look similar except the core top of $\sim 10 \mathrm{~cm}$ (Fig. 3d). MS values at the core top are larger than $20 \times 10^{-5}$ SI but decrease to $\sim 15$ $\times 10^{-5}$ SI below $\sim 10 \mathrm{~cm}$ core depth (Fig. $3 \mathrm{~d}$ ). In the core G1, this lowered MS signature can also be observed: MS values are larger above $\sim 65 \mathrm{~cm}$ core depth, even reaching a high value about $120 \times 10^{-5} \mathrm{SI}$, but dramatically decrease to smaller than $20 \times 10^{-5}$ SI below $\sim 65 \mathrm{~cm}$ core depth (Fig. 3e). Also, $\gamma$-density fluctuation of the core is relatively sharp and seems to be related to those darker laminae (Fig. 3e). Another important feature is that many gas-bubbles poured out from both core sediments with strong smells of hydrogen sulfide when the cores were retrieved onboard.

As for the site PFZ, Chirp images also show that this site has been significantly influenced by gas-plumes (Fig. 2), and thus two cores were collected individually in two OR1 cruises (OR1-1139-P1 and OR1-1164-P1). However, no clear MS anomaly is found in both MS records (Fig. 3f). MS values of both $\mathrm{P} 1$ cores are almost between $20 \times 10^{-5}$ and 30 $\times 10^{-5}$ SI with stable variation, and also long-term variations of both MS and $\gamma$-density records are roughly simultaneous. All these features indicate that MSCL variations of both P1 cores are more similar to the background sites (A2, A3, and A4). In addition, unlike the cores A6 and G1, we smelled no hydrogen sulfide during both P1 coring, implying that the cores P1 were not exactly at the right locations influenced by gases or fluids though gas-plumes were detected by the Chirp sonar at the site PFZ.

\subsection{Identification of Dominant Magnetic Minerals}

Measurement of magnetic hysteresis parameters was first completed for analyzing the magnetic minerals in these cores. In total, thirty capsule samples were collected from the cores for the measurement (dashed lines marked in Fig. 3). The Day plot was applied to present the hysteresis parameters obtained by the VSM measurements. Distribution of the ratios on the Day plot overall falls into three groups: in the upper left, lower center, and bottom right (Fig. 4). Based on the classification suggested by Horng et al. (2016), these three groups of ratio distribution may represent different kinds of the magnetic minerals dominated in the cores.

For the cores A2, A3, A4, A6, and P1, most ratios fall into the lower center area on the Day plot (Fig. 4). This kind of distribution suggests that magnetic minerals should be dominated by detrital magnetite (Horng et al. 2016). Moreover, a few ratios fall into the bottom right corner (Fig. 4), revealing the appearance of coarser detrital magnetite (Horng et al. 2016). Such type of distribution is consistent with the observation because these samples were collected at the layers with coarser grains (silty sands). As for the ratio distribution of the core G1, all ratios fall into the upper left corner (Fig. 4), implying that authigenic iron sulfides have become dominant magnetic minerals (Horng et al. 2016).
However, distribution on the Day plot may also depend on the grain size variation of magnetite (Day et al. 1977). Therefore, XRD analyses were further run to identify and confirm the dominant magnetic minerals in these cores. In total, twelve samples were collected for the XRD analysis and the sampling depths were selected based on the VSM results (red dots marked in Fig. 3). In all XRD spectra, the stronger signals mainly come from common minerals around northeastern (NE) Taiwan, such as quartz, chlorite, and albite (Fig. 5). Because all XRD spectra of the cores A2, A3, A4, and P1 show similar patterns, two results are selected as representation in the paper (Figs. 5a and b). For the signals related to magnetic minerals, the XRD spectra clearly present the dominance of detrital magnetite in these cores (Figs. 5a and b). These XRD results provide more reliable evidence that these cores may give general (background) information about sediment deposition in the southern OT.

As expected, the cores A6 and G1 are the exceptions. For the sample collected near the core top of A6, the XRD spectrum shows a similar pattern to the results from those background cores (Figs. 5a - c). That is, detrital magnetite is still the dominant magnetic minerals at the core top of A6 though the signal seems to be weaker (Fig. 5c). However, the signal of magnetite cannot be detected in the XRD spectrum for the sample at $80 \mathrm{~cm}$ core depth (Fig. 5d). These XRD results are consistent with the MS variation of the core A6 which MS values clearly decrease below $\sim 10 \mathrm{~cm}$ core depth (Fig. 3d). As for the core G1, the MS record shows strong anomaly (Fig. 3e) and the VSM result clearly indicates the appearance of iron sulfides (Fig. 4). Both XRD spectra of the core G1 also present strong signals of pyrrhotite and greigite, even the signal of pyrite (Figs. 5e and f). Results of these magnetic mineral analyses all indicate that authigenic iron sulfides instead of detrital magnetite have become the dominant magnetic minerals in the core G1.

\section{DISCUSSION}

In the past decades, several long cores have been collected in the southern OT, such as the cores MD01-2400 (MD2400), MD01-2403 (MD2403), and ODP-1202 (Bassinot and Chen 2002a, b; Richter et al. 2005a, b). No reference related to gas-features has been reported nearby these sites so these long cores might give general information about sediment deposition in this area. Core lengths of these MD and ODP cores are longer than 30 and $100 \mathrm{~m}$, respectively. Due to the limitation of the OR1 core lengths (no longer than $1.4 \mathrm{~m}$ ), only the upper parts of these long cores were used to discuss and compare with the OR1 cores in the study. Two MD cores were collected at the north of the study area nearby the East Asian continental margin (Fig. 1). Sediments are suggested to be mostly from the continental shelf, probably contributed by both northern Taiwan and China. MS values of both MD cores are almost between $20 \times 10^{-5}$ and $60 \times 10^{-5}$ 


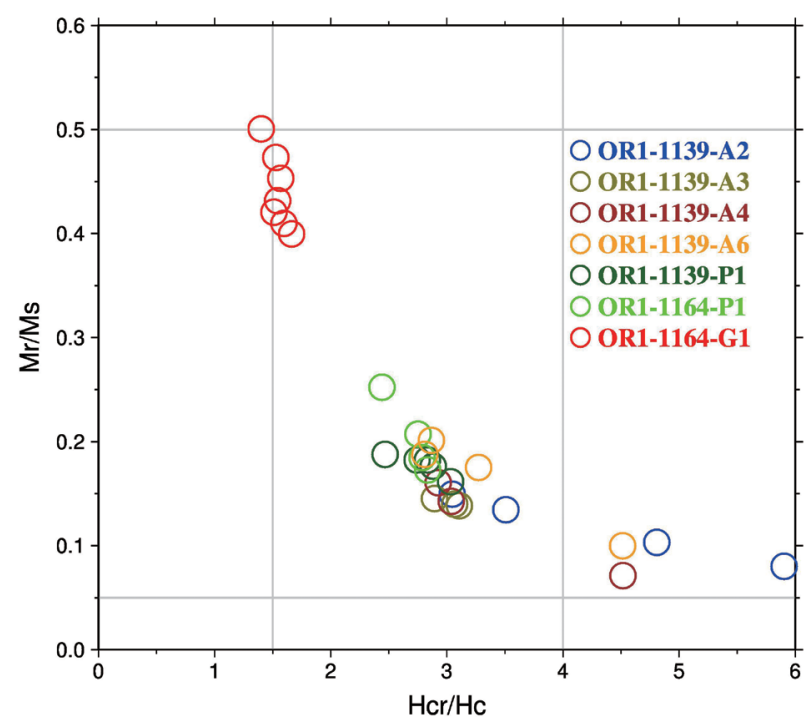

Fig. 4. Ratios of hysteresis parameters (Mr, Ms, Hc, and Hcr) graphed on the Day plot for the OR1 cores. Three groups of ratio distribution indicate different kinds of magnetic minerals dominated in the core sediments. In the lower center area: finer detrital magnetite; in the bottom right corner: coarser detrital magnetite; in the upper left corner: authigenic iron sulfides.
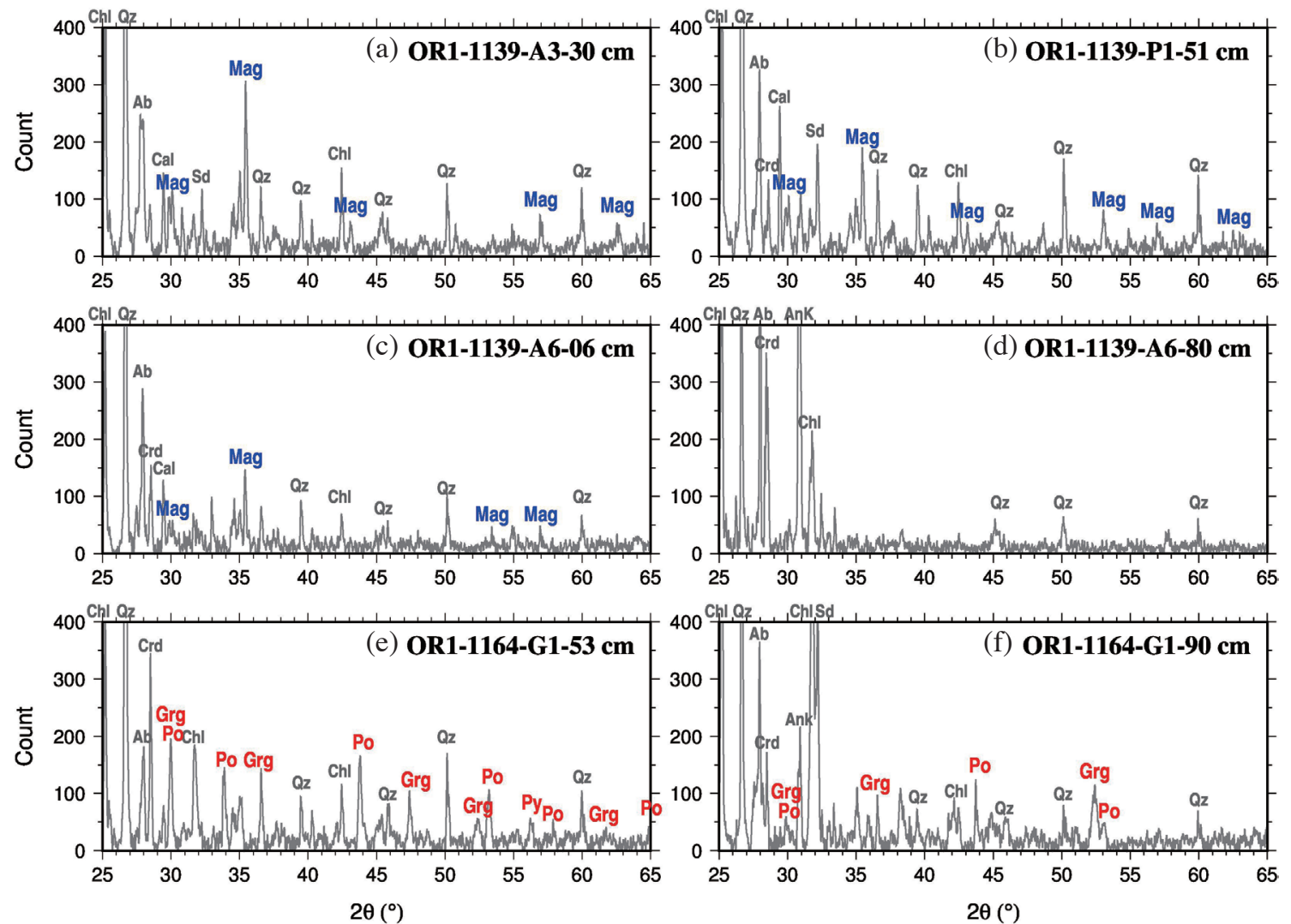

Fig. 5. Representative XRD spectra of magnetic minerals extracted from selected samples in the OR1 cores. Ab: albite; Ank: ankerite; Cal: calcite; Chl: chlorite; Crd: cordierite; Grg: greigite; Mag: magnetite; Po: pyrrhotite; Py: pyrite; Sd: siderite; Qz: quartz. 
SI except some peak values (Fig. 6a).

For the ODP-1202 sites, four cores (from 1202A to 1202D) were obtained off NE Taiwan (Fig. 1), where the average annual flux of coastal suspended sediments mainly from the rivers in NE Taiwan is about $17 \mathrm{Mt} \mathrm{a}^{-1}$ (Dadson et al. 2003). Therefore, these ODP cores should mostly consist of terrestrial (detrital) sediments. MS variations of all ODP1202 cores look similar so we take only the results of the cores ODP1202B and ODP1202D as representation in this paper (Fig. 6b). MS variations of both ODP cores decrease gradually from $\sim 30 \mathrm{~m}$ depth to the core top with values also between about $20 \times 10^{-5}$ and $60 \times 10^{-5} \mathrm{SI}$ (Fig. 6b).

For better visualization and comparison of the OR1 cores, all the MS curves were re-sorted by their ranges and then plotted together (Fig. 7). Based on the results of the cores A2, A3, A4, and P1 (Figs. 7a and b), the MS values without gas influence fall between $20 \times 10^{-5}$ and $60 \times 10^{-5}$ SI with relatively stable variation, which is consistent with those longer core records in the southern OT (Fig. 6). In addition, both hysteresis parameters and XRD analyses show that detrital magnetite is the dominant magnetic mineral in these cores (Figs. 4 and 5). These magnetic signatures reveal that these cores could provide the general deposition information of the southern OT and the background MS values should fall between about $20 \times 10^{-5}$ and $60 \times 10^{-5}$ SI with relatively stable variation, whether the sediments were mainly from northern Taiwan or East Asian continental shelf.

In contrast to the background sites, abnormal MS signature were recorded in both cores A6 and G1 (Figs. 7c and d). MS values of the core A6 are almost smaller than $20 \times 10^{-5}$ SI except the core top (Fig. 7c). By the XRD results of the core, detrital magnetite is the dominant magnetic mineral above $\sim 10 \mathrm{~cm}$ core depth but becomes absent below the depth (Figs. $5 \mathrm{c}$ and d). Because this core has been influenced by gases, we think that some redox processes have already reacted on the magnetic minerals, probably during the transition when detrital magnetite was corroded but authigenic iron sulfides were not generated yet. For the core G1, MS values are larger above $\sim 65 \mathrm{~cm}$ core depth, even reaching $120 \times 10^{-5} \mathrm{SI}$, but dramatically decrease to smaller than $20 \times 10^{-5}$ SI below this depth (Fig. 7d). Both VSM and XRD results show that dominant magnetic minerals in the core G1 are authigenic pyrrhotite and greigite (Figs. 4, 5e and f). Therefore, such strong MS anomaly could be attributed to the authigenesis of iron sulfides, which should be caused by the active hydrothermal effect.

The southern OT is considered an area with hydrothermal activity, especially nearby the Yonaguni Knoll IV. Previous study has reported that there are four active hydrothermal fields with venting fluids over $320^{\circ} \mathrm{C}$ (Suzuki et al. 2008). Moreover, several studies proposed that magnetization anomaly would be recorded around submarine hydrothermal vents based on high-resolution magnetic surveys and this anomaly was thought to be caused by the hydrothermal alternation (Tivey et al. 1993, 2014; Tivey and Johnson 2002; Szitkar et al. 2014a, b, 2015a, b; Fujii et al. 2015; Honsho et al. 2016). Recently, a high-resolution magnetic investigation with a deep-tow magnetometer has been completed nearby the Yonaguni Knoll IV (Hsu 2016). Low magnetization anomaly was observed in highly potential hydrothermal areas (Doo et al. 2019), implying that hydrothermal activity would also affect the MS values in the southern OT.

Our OR1 core sites were located around the Yonaguni Knoll IV and both cores A6 and G1 with strong MS anomaly were obtained nearby the hydrothermal fields. Gas-plumes and gas-flares, suggested to be related to the active hydrothermal effect, were evidently detected by the Chirp sonar at these sites (Fig. 2). Seafloor sulfides which generally contain iron sulfides would be generated during the hydrothermal alteration, and these authigenic iron sulfides such as pyrrhotite, greigite, and pyrite would significantly change the MS values. Therefore, the rock magnetic anomaly recorded in these cores could simply link to the authigenesis of iron sulfides related to the hydrothermal activity. One exception is at the site PFZ. Obvious gas-features were also detected at this site but no MS anomaly was recorded in both P1 cores (Fig. 7a). The reason might be that both $\mathrm{P} 1$ cores were not exactly cored at the right sites influenced by gases or fluids. An important sign is that we smelled no hydrogen sulfide during both P1 coring, evidently confirming that the cores P1 were not affected by gases. As a result, magnetic properties of both P1 cores are similar to those from the background sites.

\section{CONCLUSION}

The core sites, with and without gas-features, were selected based on the Chirp images in the southern OT. In total, seven OR 1 cores were obtained from these sites. For the core sites away from gas disturbance (A2, A3, and A4), MS variations of these cores are relatively stable with values about between $20 \times 10^{-5}$ and $60 \times 10^{-5} \mathrm{SI}$, which is consistent with the MS records obtained from nearby ODP and MD cores. In contrast, MS records of cores with gas-features (A6 and G1) clearly show the MS signature with dramatically changing values. Based on the hysteresis parameters and XRD analyses, detrital magnetite is the dominant magnetic mineral in the cores without gas disturbance while authigenic iron sulfides become significant in the cores with gas influence. The only one exception is at the site PFZ. Although gas-features were also detected at this site, both P1 cores present no MS anomaly. Hysteresis parameters and XRD results also show that the dominant magnetic mineral in both P1 cores is still detrital magnetite. The reason could be simply suggested that both P1 cores were not cored at right sites influenced by gases or fluids. Because gas-features are generally considered linking to hydrothermal activity in the southern OT, such abruptly changing MS caused by the authigenesis of iron sulfides at the sites with gas-features could also be attributed 
(a)

$\mathrm{MS}\left(10^{-5} \mathrm{SI}\right)$

(b)

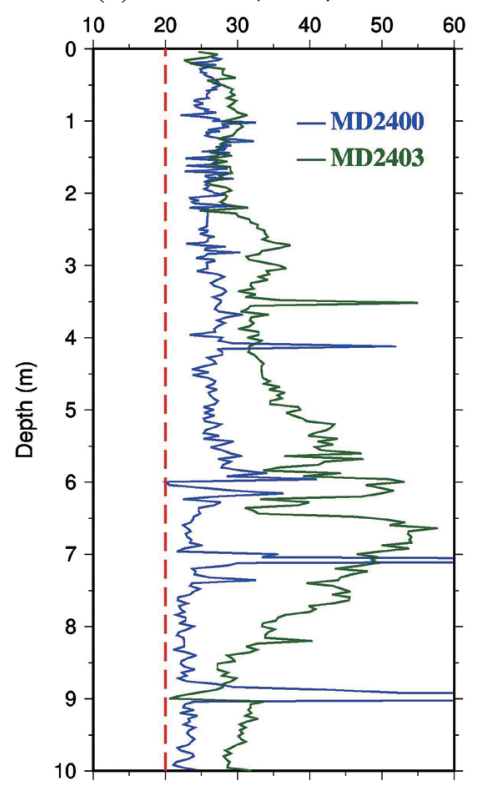

MS $\left(10^{-5} \mathrm{SI}\right)$

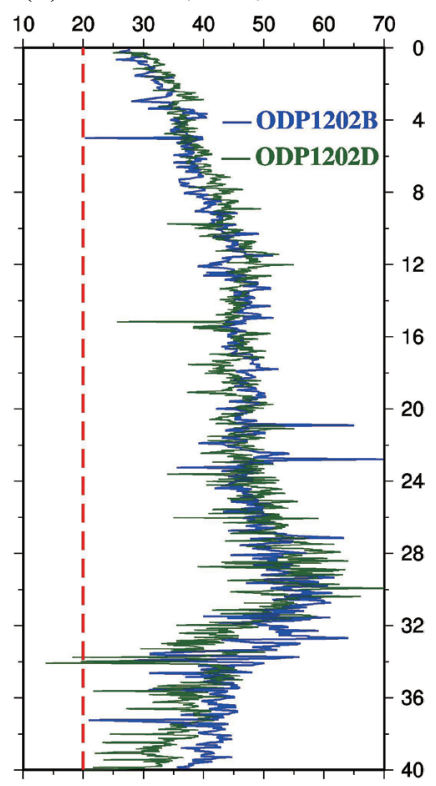

Fig. 6. Magnetic susceptibility (MS) of the previous long core records nearby the study area. (a) MS records of the cores MD2400 and MD2403 (Richter et al. 2005a, b); (b) MS records of the cores ODP1202B and ODP1202D (Bassinot and Chen 2002a, b).

(a) $M S\left(10^{-5} \mathrm{SI}\right)$

(b) $\mathrm{MS}\left(10^{-5} \mathrm{SI}\right)$

(c) $\mathrm{MS}\left(10^{-5} \mathrm{SI}\right)$

(d) $\mathrm{MS}\left(10^{-5} \mathrm{SI}\right)$
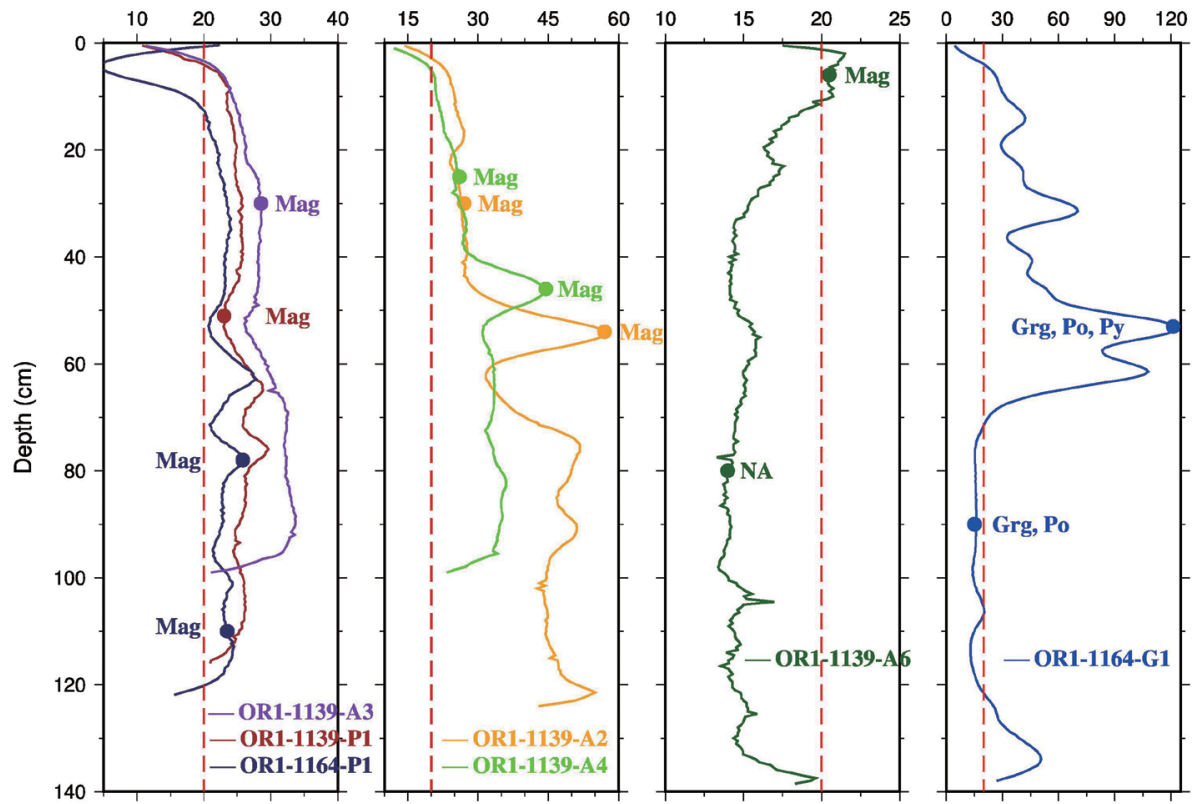

Fig. 7. Magnetic susceptibility (MS) records and XRD results of the OR1 cores. (a) OR1-1139-A3, OR1-1139-P1, and OR1-1164-P1; (b) OR11139-A2 and OR1-1139-A4; (c) OR1-1139-A6; (d) OR1-1164-G1. MS curves were sorted by their ranges and plotted together for better visualization and comparison. Dots and word marks with different colors are the XRD sampling depths and XRD results. Note that the XRD results give only the dominant magnetic minerals at the sampling layers. Grg: greigite; Mag: magnetite; Po: pyrrhotite; Py: pyrite; NA: not available. 
to the active hydrothermal effect. Rock magnetic anomaly therefore could be suggested as an indicator revealing hydrothermal activity in the southern Okinawa Trough.

Acknowledgements We would like to express our appreciation to shipboard scientific parties and the crews on the R/V Ocean Reaserch 1 during the OR1-1136, OR1-1139, and OR1-1164 cruises to collect the data and cores. We greatly thank Dr. Chorng-Shern Horng for the help on magnetic works. MSCL was measured at the Core Laboratory in the Taiwan Ocean Research Institute (TORI) and sampling works were done by the group of the Environmental Radioactivity and Sedimentology Laboratory in the Institute of Oceanography, National Taiwan University (IONTU). Magnetic measurements were completed at the Paleomagnetic Laboratory in the Institute of Earth Science, Academia SINICA (IESAS). Careful reviews by Dr. Chorng-Shern Horng and Dr. Florent Szitkar greatly improved the manuscript. The investigation was conducted by the Project of Marine Mineral Resource funded by the Central Geological Survey (CGS), Ministry of Economic Affairs in Taiwan. Most figures were plotted by using the GMT software (Wessel and Smith 1998).

\section{REFERENCES}

Bassinot, F. C. and M. T. Chen, 2002a: Physical properties of sediment core MD01-2400. PANGAEA, doi: 10.1594/PANGAEA.80057. [Link]

Bassinot, F. C. and M. T. Chen, 2002b: Physical properties of sediment core MD01-2403. PANGAEA, doi: 10.1594/PANGAEA.79901. [Link]

Cathles, L. M., 2011: What processes at mid-ocean ridges tell us about volcanogenic massive sulfide deposits. Miner. Depos., 46, 639-657, doi: 10.1007/s00126-0100292-9. [Link]

Corliss, J. B., J. Dymond, L. I. Gordon, J. M. Edmond, R. P. von Herzen, R. D. Ballard, K. Green, D. Williams, A. Bainbridge, K. Crane, and T. H. van Andel, 1979: Submarine Thermal Springs on the Galápagos Rift. Science, 203, 1073-1083, doi: 10.1126/science.203.4385.1073. [Link]

Dadson, S. J., N. Hovius, H. Chen, W. B. Dade, M.-L. Hsieh, S. D. Willett, J.-C. Hu, M.-J. Horng, M.-C. Chen, C. P. Stark, D. Lague, and J.-C. Lin, 2003: Links between erosion, runoff variability and seismicity in the Taiwan orogen. Nature, 426, 648-651, doi: 10.1038/nature02150. [Link]

Day, R., M. Fuller, and V. A. Schmidt, 1977: Hysteresis properties of titanomagnetites: Grain-size and compositional dependence. Phys. Earth Planet. Inter., 13, 260-267, doi: 10.1016/0031-9201(77)90108-x. [Link]

Doo, W.-B., S.-K. Hsu, H.-F. Wang, Y.-S. Huang, C.-H. Tsai, C.-L. Lo, S.-S. Lin, C.-W. Liang, and Y.-J. Lin, 2019: A deep-towed magnetic survey in the southern
Okinawa Trough: Implications for hydrothermal system detection. Terr. Atmos. Ocean. Sci., 30, 675-683, doi: 10.3319/TAO.2019.02.15.01. [Link]

Fujii, M., K. Okino, C. Honsho, J. Dyment, F. Szitkar, N. Mochizuki, and M. Asada, 2015: High-resolution magnetic signature of active hydrothermal systems in the back-arc spreading region of the southern Mariana Trough. J. Geophys. Res., 120, 2821-2837, doi: 10.1002/2014JB011714. [Link]

Fujikura, K., 2001: Report on investigation of hydrothermal vent ecosystems by the crewed submersible 'Shinkai 2000' on the Dai-Yon (No. 4) Yonaguni Knoll and the Hatoma Knoll, the Okinawa Trough. JAMSTEC J. Deep-Sea Res., 19, 141-154. (in Japanese with English abstract)

Gena, K., H. Chiba, K. Kase, K. Nakashima, and D. Ishiyama, 2013: The Tiger sulfide chimney, Yonaguni Knoll IV hydrothermal field, southern Okinawa Trough, Japan: The first reported occurrence of Pt-Cu-Fe-bearing bismuthinite and $\mathrm{Sn}$-bearing chalcopyrite in an active seafloor hydrothermal system. Resour. Geol., 63, 360370, doi: 10.1111/rge.12015. [Link]

Hannington, M., J. Jamieson, T. Monecke, S. Petersen, and S. Beaulieu, 2011: The abundance of seafloor massive sulfide deposits. Geology, 39, 1155-1158, doi: 10.1130/G32468.1. [Link]

Hongo, Y., H. Obata, T. Gamo, M. Nakaseama, J. Ishibashi, U. Konno, S. Saegusa, S. Ohkubo, and U. Tsunogai, 2007: Rare earth elements in the hydrothermal system at Okinawa Trough back-arc basin. Geochem. J., 41, 1-15, doi: 10.2343/geochemj.41.1. [Link]

Honsho, C., T. Ura, K. Kim, and A. Asada, 2016: Postcaldera volcanism and hydrothermal activity revealed by autonomous underwater vehicle surveys in Myojin Knoll caldera, Izu-Ogasawara arc. J. Geophys. Res., 121, 4085-4102, doi: 10.1002/2016JB012971. [Link]

Horng, C.-S., 2018: Unusual magnetic properties of sedimentary pyrrhotite in methane seepage sediments: Comparison with metamorphic pyrrhotite and sedimentary greigite. J. Geophys. Res., 123, 4601-4617, doi: 10.1002/2017JB015262. [Link]

Horng, C.-S. and K.-H. Chen, 2006: Complicated magnetic mineral assemblages in marine sediments offshore of southwestern Taiwan: Possible influence of methane flux on the early diagenetic process. Terr. Atmos. Ocean. Sci., 17, 1009-1026, doi: 10.3319/ TAO.2006.17.4.1009(GH). [Link]

Horng, C.-S., K. H. Chen, C. H. Lin, C. Y. Tseng, Y. Wang, L. Y. Fei, S. H. Chung, S. C. Chen, P. C. Chen, C. Y. Wei, and C. C. Wang, 2016: Rock magnetic properties of sediments in gas hydrate-bearing potential area offshore of southwestern Taiwan. Spec. Publ. Cent. Geol. Surv., 30, 89-122. (in Chinese with English abstract)

Hsu, S.-K., 2016: Geological Investigation of Mineral 
Resource Potential in the Offshore Northeastern Taiwan: High-resolution Sonar and Magnetic Surveys (1/4). Report of Central Geological Survey, 105-13, 238 pp. (in Chinese with English abstract)

Hsu, S.-K., 2017: Geological Investigation of Mineral Resource Potential in the Offshore Northeastern Taiwan: High-resolution Sonar and Magnetic Surveys (2/4). Report of Central Geological Survey, 106-13, 237 pp. (in Chinese with English abstract)

Ishibashi, J., F. Ikegami, T. Tsuji, and T. Urabe, 2015: Hydrothermal activity in the Okinawa Trough backarc basin: Geological background and hydrothermal mineralization. In: Ishibashi, J., K. Okino, and M. Sunamura (Eds.), Subseafloor Biosphere Linked to Hydrothermal Systems, Springer, Tokyo, 337-359, doi: 10.1007/978-4-431-54865-2_27. [Link]

Richter, C., M. H. Salisbury, M. Shinohara, and Shipboard Scientific Party, 2005a: Magnetic susceptibility on ODP Hole 195-1202B. PANGAEA, doi: 10.1594/ PANGAEA.266417. [Link]

Richter, C., M. H. Salisbury, M. Shinohara, and Shipboard Scientific Party, 2005b: Magnetic susceptibility on ODP Hole 195-1202D. PANGAEA, doi: 10.1594/ PANGAEA.266419. [Link]

Rona, P. A., 2003: Resources of the sea floor. Science, 299, 673-674, doi: 10.1126/science.1080679. [Link]

Sibuet, J.-C., J. Letouzey, F. Barbier, J. Charvet, J.-P. Foucher, T. W. C. Hilde, M. Kimura, L.-Y. Chiao, B. Marsset, C. Muller, and J.-F. Stéphan, 1987: Back arc extension in the Okinawa Trough.J.Geophys.Res.,92, 14041-14063, doi: 10.1029/JB092iB13p14041. [Link]

Sibuet, J.-C., B. Deffontaines, S.-K. Hsu, N. Thareau, J. P. Le Formal, C.-S. Liu, and ACT party, 1998: Okinawa Trough backarc basin: Early tectonic and magmatic evolution. J. Geophys. Res., 103, 30245-30267, doi: 10.1029/98jb01823. [Link]

Su, C.-C., 2016: Geological Investigation of Mineral Resource Potential in the Offshore Northeastern Taiwan: Geochemical survey and seabed observation (1/4). Report of Central Geological Survey, 105-14-A, 204 pp. (in Chinese with English abstract)

Su, C.-C., 2017: Geological Investigation of Mineral Resource Potential in the Offshore Northeastern Taiwan: Geochemical survey and seabed observation (2/4). Report of Central Geological Survey, 106-14-A, 223 pp. (in Chinese with English abstract)

Suzuki, R., J. I. Ishibashi, M. Nakaseama, U. Konno, U. Tsunogai, K. Gena, and H. Chiba, 2008: Diverse range of mineralization induced by phase separation of hydrothermal fluid: Case study of the Yonaguni Knoll IV hydrothermal field in the Okinawa Trough Back-arc Basin.Resour.Geol., 58, 267-288, doi: 10.1111/j.17513928.2008.00061.x. [Link]

Szitkar, F., J. Dyment, Y. Choi, and Y. Fouquet, 2014a:
What causes low magnetization at basalt-hosted hydrothermal sites? Insights from inactive site Krasnov (MAR 16 $38^{\prime}$ N). Geochem. Geophys. Geosyst., 15, 1441-1451, doi: 10.1002/2014GC005284. [Link]

Szitkar, F., J. Dyment, Y. Fouquet, C. Honsho, and H. Horen, 2014b: The magnetic signature of ultramafichosted hydrothermal sites. Geology, 42, 715-718, doi: 10.1130/G35729.1. [Link]

Szitkar, F., J. Dyment, Y. Fouquet, Y. Choi, and C. Honsho, 2015a: Absolute magnetization of the seafloor at a basalt-hosted hydrothermal site: Insights from a deepsea submersible survey. Geophys. Res. Lett., 42, 10461052, doi: 10.1002/2014GL062791. [Link]

Szitkar, F., S. Petersen, F. Caratori Tontini, and L. Cocchi, 2015b: High-resolution magnetics reveal the deep structure of a volcanic-arc-related basalt-hosted hydrothermal site (Palinuro, Tyrrhenian Sea). Geochem. Geophys. Geosyst., 16, 1950-1961, doi: 10.1002/2015GC005769. [Link]

Tivey, M. A. and H. P. Johnson, 2002: Crustal magnetization reveals subsurface structure of Juan de Fuca Ridge hydrothermal vent fields. Geology, 30, 979-982, doi: 10.1130/0091-7613(2002)030<0979:CMRSSO > 2.0 . $\mathrm{CO} ; 2$. [Link]

Tivey, M. A., P. A. Rona, and H. Schouten, 1993: Reduced crustal magnetization beneath the active sulfide mound, TAG hydrothermal field, Mid-Atlantic Ridge at $26^{\circ}$ N. Earth Planet. Sci. Lett., 115, 101-115, doi: 10.1016/0012-821x(93)90216-v. [Link]

Tivey, M. A., H. P. Johnson, M. S. Salmi, and M. Hutnak, 2014: High-resolution near-bottom vector magnetic anomalies over Raven Hydrothermal Field, Endeavour Segment, Juan de Fuca Ridge. J. Geophys. Res., 119, 7389-7403, doi: 10.1002/2014JB011223. [Link]

Tsai, C.-H., S.-K. Hsu, Y.-F. Chen, H.-S. Lin, S.-Y. Wang, S.-C. Chen, C.-W. Liang, and Y.-Y. Cho, 2019: Gas plumes and near-seafloor bottom current speeds of the southernmost Okinawa Trough determined from echo sounders. Terr. Atmos. Ocean. Sci., 30, 649-674, doi: 10.3319/TAO.2019.07.07.01. [Link]

Urbat, M., M. J. Dekkers, and K. Krumsiek, 2000: Discharge of hydrothermal fluids through sediment at the Escanaba Trough, Gorda Ridge (ODP Leg 169): Assessing the effects on the rock magnetic signal. Earth Planet. Sci. Lett., 176, 481-494, doi: 10.1016/s0012821x(00)00024-8. [Link]

Watanabe, H. and S. Kojima, 2015: Vent Fauna in the Okinawa Trough. In: Ishibashi, J., K. Okino, and M. Sunamura (Eds.), Subseafloor Biosphere Linked to Hydrothermal Systems, Springer, Tokyo, 449-459, doi: 10.1007/978-4-431-54865-2_34. [Link]

Wessel, P. and W. H. F. Smith, 1998: New, improved version of generic mapping tools released. Eos, Trans. $A G U, 79,579$, doi: 10.1029/98eo00426. [Link] 